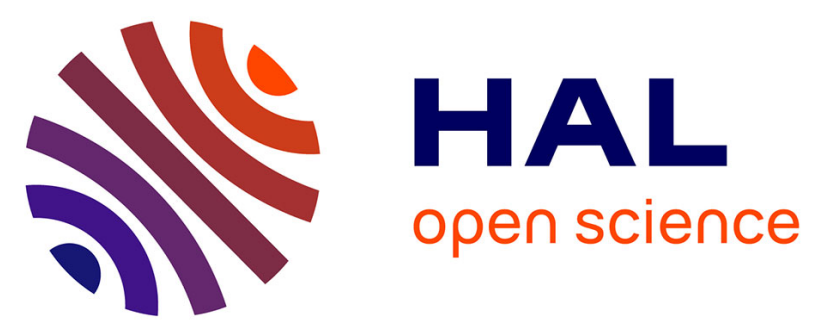

\title{
C-K theory: modelling creative thinking and its impact on research
}

\author{
Armand Hatchuel, Pascal Le Masson, Benoit Weil
}

\section{To cite this version:}

Armand Hatchuel, Pascal Le Masson, Benoit Weil. C-K theory: modelling creative thinking and its impact on research. Frédéric Darbellay, Zoe Moody, Todd Lubart. Creativity, Design Thinking and Interdisciplinarity, Springer, pp.169-183, 2017, Creativity in the Twenty First Century, 978-981-107523-0. 10.1007/978-981-10-7524-7_11. hal-01701853

\section{HAL Id: hal-01701853 \\ https: / hal-mines-paristech.archives-ouvertes.fr/hal-01701853}

Submitted on 13 Feb 2018

HAL is a multi-disciplinary open access archive for the deposit and dissemination of scientific research documents, whether they are published or not. The documents may come from teaching and research institutions in France or abroad, or from public or private research centers.
L'archive ouverte pluridisciplinaire HAL, est destinée au dépôt et à la diffusion de documents scientifiques de niveau recherche, publiés ou non, émanant des établissements d'enseignement et de recherche français ou étrangers, des laboratoires publics ou privés. 


\title{
C-K theory: modelling creative thinking and its impact on research
}

\author{
Armand Hatchuel, Pascal Le Masson, Benoit Weil \\ MinesParistech, PSL Research University \\ CGS, I3, UMR 9217
}

\begin{abstract}
Creativity has been studied as a psychological phenomenon and research has focused on factors that influence the human variability and acquisition of such capacity. Still, the creative process remained metaphorically described, and with no rigorous formalization. Moreover, the knowledge background of ideation has been ignored, as well as the interplay between creative ideation and knowledge generation. This paper is an introduction to recent advances in design theory, namely C-K theory or Concept Knowledge theory (Hatchuel and Weil 2003, 2009), that overcomes such biases and assumes that creative thinking can be formally described with solid theoretical premises that can be experimentally tested. There is now a significant literature that assesses its propositions, findings and implications. C-K theory introduces new notions: "concept undecidability", "knowledge independence", "generic expansions" and "Knowledge reordering"; they capture key necessary mechanisms of any creative process. Therefore, classic interpretations of creativity (association of ideas, analogy, blending, divergence and convergence) have to be revisited. C-K theory shows that they account for some aspects of ideation, but miss important operators that uncover the generative and expanding logic of creative thinking. It also reveals that specific knowledge structures are needed to allow for creative generation. C-K theory captures within the same formal model, both creative ideation and learning, invention and discovery, fixation and expansion of knowledge. Thanks to its explanatory and predictive power, $\mathrm{C}-\mathrm{K}$ theory allows a new articulation between theory and observation in the field of creativity. Several findings have confirmed the value of such research potential. Finally, $\mathrm{C}-\mathrm{K}$ theory stimulates transdisciplinary research through the development of a rigorous design science and the modelling of creative logic in all disciplines.
\end{abstract}

Keywords: Creativity, Design Theory, C-K theory, Design Science

\section{Introduction: creative thinking as both ideation and knowledge generation}

In this paper, we present a new approach to creativity research coming from recent advances in Design science [Le Masson, Subrahmanian and Dorst 2010] namely from the development and advancement of C-K theory [Hatchuel and Weil 2003, 2009]. This theory offers a unified and formal model for creative thinking, be it creative ideation or creative design. It also opens new paths and methodologies for research.

Traditionally, creativity has been studied as a psychological phenomenon and without any connections to Design. The literature on creativity has mainly explored two different series of research issues : i) the identification of the psychological, cultural and educational processes that favor creativity as an individual or collective mindset; ii) the study of specific traits of "creative thinking" [Boden 1999] : 
classically, creative thinking has been related to "divergent" and flexible forms of thinking; to the capacity to think "out of the box" and to welcome ideas which strongly differ from ordinary ones. But if one asks how creative thinking does work? What makes it possible? The literature only brings partial and fragmented answers. For sure, metaphors, analogies, surprising associations of ideas, illuminations, as well as serendipity have long been recognized as usual "traits" of creative thinking. Yet, if we compare the development of creativity research, to other psychological fields like decision making, behavior under risk or learning, the science of creative processes obviously lacked a sufficient level of formalization and axiomatization at least equivalent to decision theory and probability theory and this limits the analytical understanding and modelling of the creative process, or even the implementation of conclusive experiments.

\section{Revisiting standard assumptions of creativity research}

We argue that the elaboration of a formal theory of creative thinking has been hindered by two unquestioned assumptions that we have abandoned in our research programs.

a) The first assumption is the naturalistic perspective that dominates the psychology of creativity. The phenomenon under study is defined as the observed production of creative ideas or creative ideation, and research aims to capture its natural variability among individuals. It was not systematically intended to identify the type of reasoning or the models of thought through which one can generate creative ideas or explain the possibility and ontological structure of creative thought. Finally, creativity was described as a hidden psychological capacity that could only be recognized by its outputs and may be stimulated or inhibited. Contrasting with such academic trend, our research program was built on the hypothesis that creative thinking was a generic and specific reasoning process that could be made explicit and the subject of analytical study.

b) The second assumption is less visible and appears when creativity is compared to design. It is widely recognized that design can be a creative process. Yet, design is much more than pure ideation. Design is an active process that requires efforts, inquiries, tests, discussions. Thus a whole set of cognitive activities (learning, comparing, arguing ...) contributes to creative design. Therefore, we should have learned from design activity that creative thinking encompasses two different processes: i) creative ideation; ii) a process of knowledge generation, in relation with some context and environment. In common words, creativity research has approached creative ideas as pure inventions of the mind, while Design research had to account both for such inventions and for cognitive discoveries that may be provoked or emerge during the design process.

These preliminary remarks have major scientific implications: a) the ideation process should necessarily be associated to a knowledge process; b) yet, what are the interactions between ideation and knowledge generation? What is generated by such dual processes? These issues played a key role in the development of the research program that led to the elaboration of C-K theory (Hatchuel and Weil 2001, 2003) and this paper aims to be an introduction to this theory and to its main findings. Before, let us indicate some of the immediate consequences of the previous remarks.

\section{The missing background: Revealing the role of knowledge in the creative process}

If creative thinking is interpreted as the design of an idea, even if it is purely mental and partly unconscious, it becomes necessary to associate to creative ideation, a cognitive process where knowledge activation, organization, and evaluation also take place in the mind. Actually, it is easy to admit that the memory and past knowledge (of all types) of a subject acts as a complex and evolving cognitive resource that will impact ideation. It is however less intuitive to consider that ideation can also impact memory and knowledge. But a new and more rigorous perspective appears: where ideation is distinguished, yet not separated, from its cognitive resources, and both should be seen as potentials for mutual activation and development. 
This new approach leads, at first, to critically revisit classic propositions from creativity research.

Revisiting convergent thinking and divergent thinking. The distinction between divergent thinking (DT) and convergent thinking (CT) is at the root of the psychological description of creative ideation [Guilford 1959, Torrance 1988]. DT was traditionally seen as enabling novelty i.e. the definition of some new entity; whereas CT was needed for value achievement and control, i.e. giving reality and relevance to this new entity [Cropley 2006, Eris 2004]. Yet, if we do not take into account the knowledge process coupled to the ideation process, the impact of DT and CT becomes undetermined. DT followed by CT can lead to poor creativity if the most original ideas generated by DT are rejected because of a lack of knowledge to elaborate them. Conversely, CT can also contribute to novelty by warranting feasibility to the most creative ideas of the process. Therefore the divergence/convergence model is not sufficient to explain novelty and value. What is missing is the specific knowledge content which activates CT or DT and their combinations. Without a clarification of the interplay between knowledge processes and standard notions like CT and DT, it was also not surprising that the impact of "expertise" on the creative processes remained controversial.

The role of expertise: prison or escape tool? The potential tension between existing expertise (skilled knowledge) and creativity is well described. Weisberg [Weisberg 1999] suggested that existing competences limit novelty but are needed for value achievement. According to Boden, a creative idea cannot be produced by "the same set of generative rules as are other, familiar ideas" (p.40) [Boden 1990]. It was also observed that value would require specific expertise whereas novelty comes mainly from general and abstract models [Ward, Smith and Finke, 1999]. It is also common place that expertise matters: ideas appearing as novel to some people may present no such novelty for an expert. Finally, if we take into account the interaction between ideation and knowledge processes, the impact of expertise on creative processes cannot be predicted in advance. It can be both a resource and an obstacle for the creative process.

The conditions of creative generation: unknown objects and the changing of object definitions. Any creative process aims to generate new artefacts and new ideas. This implies a necessary condition that is often overlooked, yet is key to the understanding of the underlying creative mechanisms. One have to assume the progressive description of objects that were necessarily partly unknown when the creative activity begins. Moreover, as already stated before, "unknown" is always relative to some state of knowledge associated to the creative process. Thus, a crucial and necessary operation of the creative process is the activation of old and new knowledge in order to temptatively define and make exist some unknown objects. The operation that transforms unknown objects into new known ones plays a major role in the formalization of the creative process. Boden underlined the notion of "transformational creativity" and stressed the need to change "the generative rules of familiar ideas". But this formulation may have been misleading for creativity research. Transforming ideas is not enough to obtain a creative process. What is necessary is to transform previous knowledge and previous definitions of objects. "Objects" or "things" are organizers of knowledge that have to be transformed by generative rules [Abadi and Cardelli, 1996]. Actually, the basic generative rules of any language or knowledge background are those that stabilize or change the definition, be it syntactic or semantic, of "objects" (i.e. "names", sorts, or relations between names). Thus, any creative process is the transformation of existing knowledge by introducing new objects and maintaining the definition of older ones.

Finally, it is more rigorous and general to define creative thinking as the temptative elaboration of new objects, rather than new ideas. Moreover, the interplay between the redefinition of objects and the generation of new knowledge, ignored by standard creativity research, appears as a central mechanism of creative thinking. So far, these first conclusions indicate that any rigorous and consistent formalization of creative thinking have to capture and integrate these interplaying elements within a same formalized model. These were the objectives of $\mathrm{C}-\mathrm{K}$ theory that we introduce in the next section. 


\section{Elements of $\mathrm{C}-\mathrm{K}$ theory: the dual expansion of concepts and knowledge}

C-K theory (an acronym of Concept Knowledge theory) has been introduced by Hatchuel and Weil [Hatchuel and Weil 2003, Hatchuel and Weil 2009] as a model of creative design. It has now important scholarly developments and a wide range of applications in research and practice [Agogué and Kazakci 2014]. The name "C-K theory" mirrors the assumption that creative Design can be modelled as the interplay between two interdependent spaces having different structures and logics: the space of concepts (C) and the space of knowledge (K). The structures and expansions of these two spaces determine the core propositions of $\mathrm{C}-\mathrm{K}$ theory. In this paper, we only insist on the implications of $\mathrm{C}-\mathrm{K}$ theory for our understanding and research about creative thinking,

\subsection{The two spaces $C$ and $K$ : basic assumptions.}

Space $\mathrm{K}$ is expandable and contains all established (true) propositions (the available knowledge). It makes explicit the missing background of any creative process that was already mentioned. It plays several roles: it is a reference space, a resource space and an output space that is transformed during the creative process. Knowledge is the collection of established true propositions ${ }^{1}$, from the point of view of a "creative" person or group of persons.

Space C is also expandable and is the space where "creative ideation" is explicitly organized. Yet, we have to give to this expression a more precise definition: we call "creative ideation", the temptative and progressive definition (or description) of a partially unknown, yet desirable, object. Such definition is always relative to a certain state of space $\mathrm{K}$. Thus space $\mathrm{C}$, is the space where new definitions of objects are progressively elaborated. Whereas, Space $\mathrm{K}$ is the space that contains all available knowledge that is used by the definitional process in space C. In standard approaches of creativity, only space $\mathrm{C}$ is observed and space $\mathrm{K}$ is ignored.

More technically, in C-K theory, the attempting definitions of new objects in space $\mathrm{C}$ are called concepts, and the formalism of $\mathrm{C}-\mathrm{K}$ theory has allowed to establish that: Concepts are propositions about some partially unknown objects $\mathrm{X}$ and are all of the form: "There exists some object $\mathrm{X}$, for which a group of properties P1, P2, Pk hold in K". Moreover, it can be proved that if concepts are about unknown objects then concepts are undecidable propositions in $\mathrm{K}$ (neither true nor false in $\mathrm{K}$ ). Concepts define unusual sets of objects: they are sets of partly unknown objects, which implies that their elements have an existence that is not warranted in $\mathrm{K}$. The sets of Space $\mathrm{C}$ are special sets which can be defined by classic axioms of Set theory (ZF), excepting those that assume the existence of elements (like the axiom of Choice which has to be rejected). Yet important results in Set theory have established that this rejection could be done without impact on the other axioms [Cohen 1963] $]^{2}$.

Having defined Space $\mathrm{C}$ and Space $\mathrm{K}$, the creative process can be formalized as the process by which undecidable concepts - that are usually called ideas or "briefs" in design activities are generated and transformed into one or several new objects, i.e. true propositions of K. New ideas or design solutions

\footnotetext{
${ }^{1}$ Regardless of how "truth" is assessed. For instance emotions can be seen as "truths" that can impact the creative process as any other type of truths, for instance, "scientific"propositions. This flexibility in the construction of space $\mathrm{K}$, gives to $\mathrm{C}-\mathrm{K}$ theory a very high level of generality and allows to capture and understand creative processes and different types of human activity.

${ }^{2}$ Moreover, it has been established that $\mathrm{C}-\mathrm{K}$ theory was in deep correspondence with the Forcing method in Set theory [Cohen 1963] Forcing is a major result of Modern Set theory; it has been developed in 1963 by Paul Cohen for the design of new collections of sets (called extension models). Thus Forcing can be interpreted as a method for creative design in the pure world of sets. And to put it shortly, if space K is limited to Set theory and number theory, $\mathrm{C}-\mathrm{K}$ theory becomes the Forcing method. Thus $\mathrm{C}-\mathrm{K}$ theory can be seen as a generalization of forcing to knowledge spaces where objects are not only numbers or classic sets [Hatchuel and Weil 2007, Hatchuel, Le Masson and Weil 2010].
} 
are selected among these new propositions. During the design process $\mathrm{C}$ and $\mathrm{K}$ are jointly expanded through the action of four different $\mathrm{C}-\mathrm{K}$ operators that reveal the hidden and ignored complexity of creative thinking.

\subsection{The design process and the four C-K operators.}

According to $\mathrm{C}-\mathrm{K}$ theory, design proceeds in space $\mathrm{C}$, by a step by step partitioning of $\mathrm{C}$ sets using propositions coming from $\mathrm{K}$. Beginning with a first concept $\mathrm{C} 0$, the partitioning operation is repeated whenever there is a partitioning proposition in $\mathrm{K}$ and until some partitioned " $\mathrm{Ci}$ " becomes a new object "Ki" i.e. an object which existence is warranted by propositions in K. Under such construction, the following propositions hold [Hatchuel and Weil 2003, 2009]:

Space $\mathrm{C}$ takes necessarily a tree expanding structure which describes the expansion of $\mathrm{C} 0$ (see fig 1). Therefore this proves why the opposition between divergent and convergent thinking was misleading. Any attempt to define new objects (things, methods, solutions) gives birth to divergence and refinement. Creativity only appears if the interplay between such divergence and the knowledge generation gives birth to established new objects

Space $\mathrm{K}$ is necessarily expanded by the operations of evaluation and activation that are triggered by $\mathrm{C}$ expansions. In classic terms, creative ideation not only transform ideas but also provokes the generation of new knowledge, which is the necessary conditions for transforming concepts into objects. Again, C-K theory reveals central mechanisms of creative thinking that were ignored by standard approaches that were guided by a biased notion of "ideation".

$\mathrm{C}-\mathrm{K}$ theory predicts the necessity of four types of operators: $C \rightarrow C, C \rightarrow K, K \rightarrow K$, and $K \rightarrow C$. Implicitly, standard approaches of creativity were focused on $K \rightarrow C$ operations: generating novel ideas finding. This left in the dark, three other operators. I) $\mathrm{C} \rightarrow \mathrm{C}$ operators which organize the progressive refinement and structuring of ideation and is precisely where creative reflexivity, i.e. judgements on originality, novelty, value can be developed. II) $\mathrm{C} \rightarrow \mathrm{K}$ operators which transform ideation into new knowledge, and not only capture all validation practices (sketches, tests, prototypes, mock ups...), but also new independent sources of knowledge; and finally $\mathrm{K} \rightarrow \mathrm{K}$ operators which not only contain classic reasoning, but also re ordering operations that allow a new object to be integrated to other old objects without creating loss of meaning and nonsense.

The identification of these four operators reveals a completely new understanding of creative thinking. Not only they invite to a complete new phenomenology of creation, but they also provide a unique and rigorous formalism, i.e. a scientific model, that captures creative design and was lacking since the early days of the field

\subsection{The generic mechanism of creative power: expanding partitions and knowledge expansions.}

One key prediction of C-K theory deserves a more detailed description: the distinction between two types of $\mathrm{C}$ partitions, i.e. between two types of refinements in the $\mathrm{C}$ space.

- If the partition expands the definition of an object with a new property that is not known in $K$ as a possible property of this object, it is called an expanding partition.

- Conversely, if the partition relies on an existing definition or property of the object in $K$, it is called a restricting partition.

For instance, "a house with a red roof" is a restricting partition if "houses with red roofs" are already known in K; "A house without roof" is an expanding partition if there is no such types of houses in K. Moreover, C-K theory tells us that this notion cannot be defined per se, it is always relative to a certain space $\mathrm{K}$ that should be made explicit to recognize the expanding type of the partition. 
It is easy to see that the notion of "expanding partition" rigorously describes a generic operation that unifies a large collection of operations that were usually seen as the "spark" of the creative process: metaphors, analogies, idea associations, illuminations and so on.... By generic we mean that the expanding partition opens the path to the generation of new objects, and it can occur on all types of description of an object (structural, physical, sensorial...) and at all levels of definition of this object. Now, a key finding of C-K theory is that expanding partitions are a necessary but not sufficient, instrument of creative thinking. New objects will appear, only and only if, K expansions (new K) allow to continue the refinement and definition of expanding partitions until a concept becomes "reality", i.e. a decidable (and decided) truth in K. Figure 1 synthesizes the four C-K operators and their interplay.

Figure 1. C-K design process and its operators.

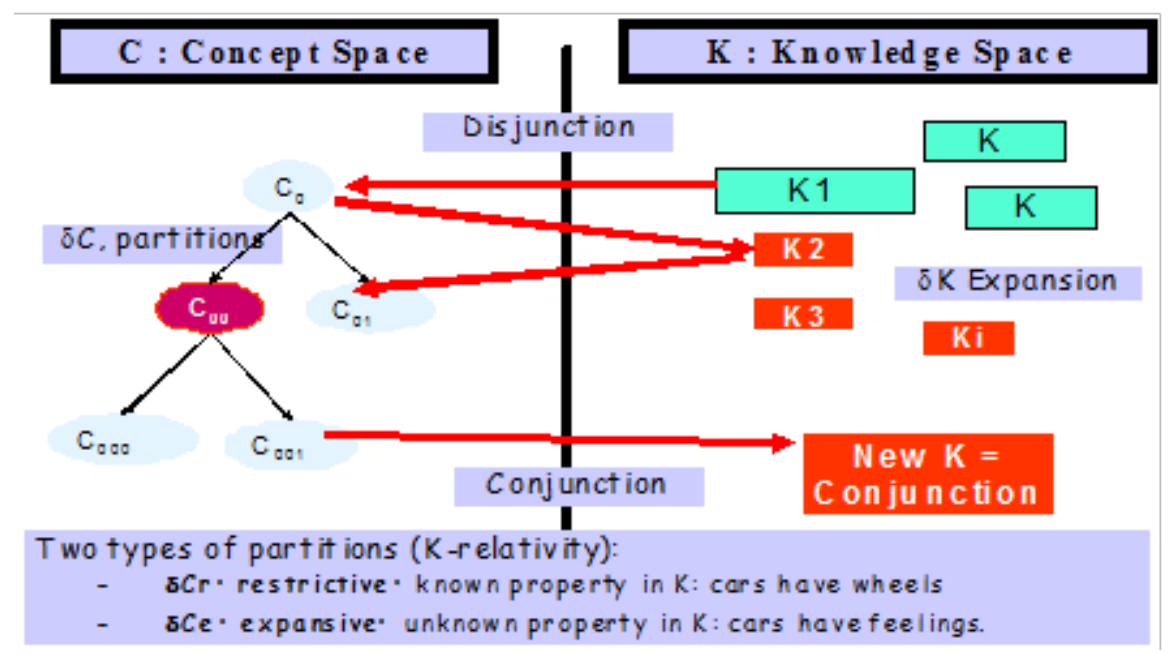

\section{A scientific model of creative thinking: a synthesis in five propositions.}

$\mathrm{C}-\mathrm{K}$ theory offers a model that rigorously capture and understands the creative process. This claim can be synthesized through five propositions that step by step reinterpret classical notions and offers an operational, predictive and consistent theory of creative design that can be easily tested by empirical observations or applications.

P1. Design and creativity are C-K processes. Design needs usually some initial requirements while creativity may have no clear starting point. C-K theory can model both processes. In design some C0 may be stated at the beginning of the process by some external person that is not the designer. But C-K theory can be equally seen as a continuous and recursive process: propositions in $\mathrm{C}$ are generated continuously and expanded through a $\mathrm{C}-\mathrm{K}$ process. This fits quite well with the description of creativity as a self-triggering mode of thinking.

P2. Novelty and value are $K$ dependent and generated by joint $C-K$ expansions. Even if novelty is defined as some new object appearing for "the first time in history", this is still a $\mathrm{K}$ dependent definition. History is simply the name we give to our knowledge about the past. The same argument stands for value. Any value criteria is a piece of established knowledge in the social system where creativity and designed are situated (be it the opinion or emotion of a user or a client). Thus novelty 
and value are not external to the design process and are embedded in $\mathrm{K}$. If a client rejects a design, this only means that sufficient knowledge about its needs was lacking or wrong in $\mathrm{K}$.

Novelty is necessarily triggered by one or several expanding partitions. Yet, the knowledge used to form these partitions could have been present at the beginning of the process (existing one) or generated during the process (new one). Moreover, designed solutions will not use all the partitions developed in $\mathrm{C}$, and will be composed by a list of attributes mixing restrictive and expansive partitions. A creative solution is a design that may combine knowledge generated by all different paths in $\mathrm{C}$. Thus, the whole expansion in $\mathrm{C}$ and the whole expansion $\mathrm{K}$ could have contributed to form novelty. Similar arguments hold about value. A corollary proposition is that novelty and value are not contradictory. C-K theory shows no such thing. Space C and Space K are not in opposition they are co generated.

P3. Expanding partitions generate new propositions in $\mathbf{C}$ and in $\mathbf{K}$. This is one of the deepest results provided by $\mathrm{C}-\mathrm{K}$ theory. It can be imaged as such: the "crazy" ideas allowed in $\mathrm{C}$ have two modes of action: 1) they can open a new path in $\mathrm{C}$;2) they can activate new knowledge in $\mathrm{K}$ that may, in return, form a new more valuable concept expansion elsewhere in $\mathrm{C}$. These two different mechanisms explain the seemingly irrational process of creativity when rationality is only defined as the result of standard KàK operator's i.e. Classic logic. In Space C, thanks to the undecidability of concepts, any strange associations of concepts (ideas) can be formulated without provoking contradiction or nonsense in K. They would have no impact unless the generated Knowledge transforms these strange ideas into a creative and decidable design in $\mathrm{K}$. Thus, $\mathrm{C}-\mathrm{K}$ operators provide a rational process that transforms irrational propositions into new valid knowledge and creative designs!

P4. C-K theory captures all forms of creativity. The interplay of C-K captures a wide range of possible expansions in $\mathrm{C}$ and $\mathrm{K}$ as well as well-known types of creativity like the following:

- Pseudo creativity is easily modelled by a wide expansion in $\mathrm{C}$ which never generates any expansion in K. A lot of surprising partitions are produced yet none of them can be transformed into decidable propositions.

- Bounded creativity can be related to two different types of C-K expansions. I) a wide expansion in $\mathrm{C}$ is generated but a small subset of $\mathrm{K}$ blocks almost all alternatives. II) Few alternatives are generated through the activation of a small subset of $\mathrm{K}$. in both cases we can find the existence of a dominant subset of $\mathrm{K}$ (fixated knowledge) which either kills any new concepts or even impedes their formation. In practice, these two types of creativity are quite different.

P5. Creative thinking and design conveys a redefinition of objects and a re-ordering in $K$. The path from and undecidable concepts to decidable solutions is warranted by expansions in $\mathrm{C}$ and $\mathrm{K}$ spaces. These expansions can be of little impact on the general structure in K. Yet, in some other cases, it is the definition of a common class of objects (an ontology) that have to be changed or created. For instance, when electricity was used to transport sounds or voices, a new complete class of objects appeared (the telephones) and the definition of other ways to transmit sound had to be revised. Such necessary reorganization of $\mathrm{K}$ is necessary to preserve meaning and consistency, it is also a condition to regenerate independences that will allow for new $\mathrm{C}$ expansions: creative thinking nurtures the creative potential. 


\section{An intuitive interpretation of $\mathrm{C}-\mathrm{K}$ theory: chimeras, discoveries, re ordering of objects and knowledge}

C-K theory does not contradict standard knowledge about creativity but it reveals unique and hidden features of creativity thinking that were neglected or mistakenly treated. In addition, these features allows to perceive creative thinking as a rational, rigorous and consistent logic that was not yet described and explicitly unveiled.

Creative thinking needs "ideas" but not all ideas can trigger creativity. Likewise not all metaphors, analogies, unusual association can be at the root of a creative process. Something additional is required: that the new idea expresses a "chimera", a description of a new entity that is defines by attributes that are connecting "independent" pieces of existing knowledge; and this independence is not universal, it is relative and contextual to a specific structure of knowledge. Yet, this relativity was not analyzed and not seen as a resource for creativity. If we visualize a chimera as a "hole" in existing knowledge (Hatchuel et al...), we understand that creative thinking would disappear if there was no such holes in our knowledge.

Traditionally, chimeras are imaginary monsters, half man and half animal. They com bine properties that came from knowledge about humans and knowledge about animals, properties that are not connected in $\mathrm{K}$. Yet, in modern science, a man can live with animal implants. These are no more chimeras. Chimerization is the intuitive image that fits well with the abstract notion of expanding partitions.

Yet, chimerization is only one operator of creative thinking. Discoveries are also needed, creative thinking needs the provocation of surprising learnings. Creative thinking has to be an active and inquiring process. But not all surprises will transform a chimera into a real thing! Creative thinking generates knowledge in excess, knowledge that finds itself useless.

Chimeras become reality thanks to cognitive conquests. But chimeras are also themselves good triggers for the activation and exploration of new independent sources of Knowledge! Monsters stimulate reflexivity and invite to search for new means (new K) to make them exist or to temper their strangeness.

Now when monsters come to existence, by design, they force to rethink old things and established relations. Creative thinking needs re organizing, re-structuring, re shaping of things. This is not a process that is outside creative ideation, it is an essential part of it. Creative thinking is not only about one new thing, it also addresses the re ordering of the available knowledge that is required to "host" the new thing in a consistent and meaningful way.

Finally, the intuitive perception was that creativity was irrational and irrationality was the condition of creativity. As it is often the case, this intuitive perception was not wrong but it was biased and incomplete due to unquestioned assumptions that distorted observations and research. C-K theory suggests that creative thinking is completely rational when its dual logic and context is clarified. It is a 
general form of design that is independent of what is designed. It can be also interpreted as the rationality of any generation process.

\section{Conclusion: implications and applications of C-K theory for research}

The elaboration of a formalized model of creative thinking has important impact on research issues and methods. A wide range of new programs become possible thanks to the variety of analytical properties and predictions that may be derived from the model. In the following section, we will mention some programs and their published findings that have been allowed using $\mathrm{C}-\mathrm{K}$ theory.

\section{Capturing forms of creative thinking in different fields (art, science, and engineering).}

$\mathrm{C}-\mathrm{K}$ theory generates many testable predictions. One of them, mentioned previously, is that to allow for the generation of a new object in $\mathrm{C}$, the structure of the $\mathrm{K}$ space has to present "independences" that will be transformed. More operationally, this means that the $\mathrm{K}$ space has neither a deterministic structure (all thinking is reduced to deductions, no independence), nor a modular one (all thinking is reduced to free combination of existing and compatible bricks: no independence) ((Le Masson P., Hatchuel A., Weil B. 2016). Thus one could predict that the task of Art based schools would be to restructure student's knowledge in order to ban determinism and modularity. The validity of this prediction was confirmed (Le Masson P., Hatchuel A., Weil B. 2016) by recent research that studied the teachings of famous Bauhaus professors such as Paul Klee and Johannes Itten. This finding also contributed to explain the prominent role of Bauhaus in the creation of new styles in a wide range of industrial designs. It has also contributed to a new understanding of sketching, not as a process of idea expression as usually seen, but also as media for the re ordering of knowledge (Brun J. et al. 2015).

Relying on contemporary $\mathrm{C}-\mathrm{K}$ theory it was also possible to identify a different creative logic in engineering design and science (Le Masson P., Hatchuel, Weil B., 2011 2013). To preserve robustness and easy design, engineers tend to favor determinism and modularity in the structuring of their actionable knowledge. However, engineering science frees the engineer from fixated relationships between functions and organs. Performance, functions, use cases and, specifications trigger new concepts as unknown combinations and hence promote creativity. Moreover, Science is regularly re ordered to integrate discoveries and new objects or to allow constant regeneration with limited re ordering. Thus $\mathrm{C}-\mathrm{K}$ theory invites to avoid any dogmatic views about how to teach creative thinking. The same theoretical model can guide towards different forms of teaching that are adapted to the special expansions of $\mathrm{C}$ and $\mathrm{K}$ that fit with one specific domain, depending on its ontology (objects and knowledge) and epistemology (theory of truth).

\section{Building new theory driven experimental protocols}

Thanks to its rigor and predictions, C-K theory enables the design of theory driven experimental protocols in design and creativity research. Without clear theoretical frameworks, experimental research may lead to weak findings and even to general inconclusiveness. This was the case in the various experiments that have been conducted in order to know whether examples tend to fix or de fix ideation processes (Agogué M., Cassotti M. 2012). C-K theory predicts that examples will play a different role if they belong to the fixation zone in Space and K, or if they do not belong to this zone (ie. Belong to the "expanding" zone). The problem is that the fixation zone is K dependent and have to be identified before the experimentation. This prediction allowed to design a new set of experiments 
where the impact of the examples became highly predictable, proving that without the control offered by $\mathrm{C}-\mathrm{K}$ theory, hidden variables existed in previous experiments (Agogué M. et al. 2014).

More generally, C-K theory could have predicted and explained a large variety of observations that appeared in design experiments: namely "generative design questions" (Eris 2003, 2004); the emergence of new nouns by recording noun phrase in design exercises (Mabogunje and Leifer 1997). $\mathrm{C}-\mathrm{K}$ theory also helps to formulate hypotheses and follow experiments based on specific types of design media like sketching (Brun et al. 2015). It contributed to confirm the differences resulting from specific forms of design reasoning between design professions (Savanovic P. and Zeiler W. 2007; Agogué M. et al. 2015). In brainstorming experiments, design theory predicts the low generative power of brainstorming: theory predicts that the quantity of ideas is not related to originality and quality as originality is also $\mathrm{K}$ dependent; it also predicts that focusing on de fixing concepts generates more new knowledge and hence more original ideas and design value comes from the consistent use of this new knowledge (Kazakçi A.O. et al. 2014).

\section{Supporting a transdisciplinary paradigmatic shift: design science as a science of creative thinking and processes}

$\mathrm{C}-\mathrm{K}$ theory leads to new connections with contemporary mathematics and logic. It has stimulated the new notion of imaginative constructivism (Kazakçi A.O; 2013) that generates new bridges between creation and brouwerian constructivism. C-K theory also helps modelling new approaches of system engineering and technology management (Kokshagina 2014). C-K theory provides a solid ground for the merging of design theory and creative thinking theory. This helps to clarify the ontology of design and can nurture a wide range of human and social studies of design (sociological, anthropological, organizational, epistemological and linguistic studies). An example of such impact is the notion of "common unknown" that allows to understand the governance of collective design situations (in firms or in non profit-organisations) where creative thinking is needed not only about means of action but also about the ends to be generated and reached (Le Masson P. and Weil B. 2013)

Hence, C-K theory appears today as a solid scientific ground for a transdisciplinary shift. Creative processes are better understood and modelled within Design theory and science. Then, such new science can contribute to research on human activities that were already seen as creative; it can also help studying creative forms in domains where they are less visible or hidden. Finally, creative thinking is no more reduced to a psychological and natural phenomena, it reveals a forgotten class of scientific thinking, the generic design of unknown objects and its co expansion with the transformation of knowledge. Through the formalization of $\mathrm{C}-\mathrm{K}$ theory such paradigmatic shift has already opened new ways of research and provided unexpected findings. Yet, all this could be only the early steps of a much wider scientific impact.

\section{References}

Abadi M and Cardelli L (1996) A Theory of Objects Springer, New York

Agogué M, Cassotti M (2012) Theory driven experiments : modeling and testing fixation and stimulation effects on creativity. Paper presented at the 5th Paris Workshop of the Design Theory SIG, Paris, 30th January 2012, 
Agogué M, Kazakçi A (2014) 10 years of C-K theory: a survey on the academic and in dustrial impacts of a design theory. In: Chakrabarti A, Blessing L (eds) An Anthology of Theories and Models of Design. Philosophy, APproaches and Empirical Explorations. Bangalore, pp 219235. doi:10.1007/978 1447163381

Agogué M, Kazakçi A, Hatchuel A, Le Masson P, Weil B, Poirel N, Cassotti M (2014) The impact of type of examples on originality: Explaining fixation and stimulation ef fects. Journal of Creative Behavior 48 (1):1 12 .

Agogué M, Le Masson P, Dalmasso C, Houdé O, Cassotti M (2015) Resisting classical so lutions: The creative mind of industrial designers and engineers. Journal of Psychology of the Aesthetics, Creativity and the Arts (accepted).

Boden M (1990) The creative mind George Weidenfeld and Nicolson Ltd, Great Britain

Boden MA (1999) Computer Models of Creativity. In Sternberg, R.J., ed. Handbook of creativity, pp. 351372 Cambridge University Press, Cambridge.

Brun J, Le Masson P, Weil B (2015) Analyzing the generative effects of sketches with design theory: sketching to foster knowledge reordering. In: International Conference on Engineering Design, Milan, 2015.

Cohen PJ (1963) The independence of the Continuum Hypothesis. Proceedings of the National Academy of Science, 50: 11431148.

Cropley A (2006) In Praise of Convergent Thinking. Creativity Research Journal, 18, (3): 391404.

Eris $\mathrm{O}$ (2003) Asking generative questions: a fundamental cognitive mechanism in design thinking. In: International Conference on Engineering design, ICED'03, Stockholm, 2003.

Eris O (2004) Effective Inquiry for Innovative Engineering design. Kluwer Academic Publisher, Boston

Freitas Salgueiredo C, Hatchuel A (2016) Beyond analogy: A model of bio inspiration for creative design. AI EDAM (accepted)

Guilford JP (1959) Traits of Creativity. In Anderson, H.H., ed. Creativity and its Cultiva tion, p. 1426161 Harper. 
Gero JS (1990) Design prototypes: a knowledge representation schema for design. AI Magazine, 11, (4): 2636.

Hatchuel A and Weil B (2003) A new approach of innovative design: an introduction to C-K theory. ICED'03, august 2003, Stockholm, Sweden.

Hatchuel A and Weil B (2007) Design as Forcing: deepening the foundations of C-K the ory. International Conference on Engineering Design, Paris.

Hatchuel A and Weil B (2009) C-K theory : an advanced formulation, Research in Engi neering Design, 19, 181192

Hatchuel A, Weil B, Le Masson P (2013b) Towards an ontology of design: lessons from C-K Design theory and Forcing. Research in Engineering Design 24 (2):147 163.

Kazakçi AO (2013) On the imaginative constructivist nature of design: a theoretical ap proach. Research in Engineering Design 24 (2):127 145.

Kazakçi AO, Gillier T, Piat G, Hatchuel A (2014) Brainstorming vs. Creative Design Rea soning: A Theory Driven Experimental Investigation of Novelty, Feasibility and Value of Ideas. Paper presented at the Design Computing and Cognition'14, London, UK,

Kokshagina O (2014) Risk Management in Double Unknown: Theory, Model and Organ ization for the Design of Generic Technologies. MINES ParisTech, Paris

Le Masson P, Hatchuel A and Weil B (2007) Creativity and Design Reasoning: How C-K Theory can enhance creative design. International Conference on Engineering Design, ICED'07, Paris.

Le Masson P, Dorst K, Subrahmanian E (2013) Design Theory: history, state of the arts and advancements. Research in Engineering Design 24 (2):97 103.

Le Masson P, Hatchuel A, Weil B (2011) The Interplay between Creativity issues and Design Theories: a new perspective for Design Management Studies? Creativity and Innovation Management $20(4): 217237$.

Le Masson P, Hatchuel A, Weil B (2016) Design theory at Bauhaus: teaching "splitting" knowledge. Research in Engineering Design 27 (April 2016):91 115.

Le Masson P, Weil B (2013) Design theories as languages for the unknown: insights from the German roots of systematic design (1840 1960). Research in Engineering Design 24 (2):105 126. 
Mabogunje A, Leifer LJ (1997) Noun Phrases as Surrogates for Measuring Early Phases of the Mechanical Design Process. In: 9th international Conference on Design Theory and Methodology, American Society of Mechanical Engineers, September 14 17, Sacramento, CA, 1997. p 6

Mabogunje A, Leifer LJ (1997) Noun Phrases as Surrogates for Measuring Early Phases of the Mechanical Design Process. In: 9th international Conference on Design Theory and Methodology, American Society of Mechanical Engineers, September 14 17, Sacramento, CA, 1997. p 6

Pahl G and Beitz W (2006) Engineering design, a systematic approach Springer, Berlin

Redelinhuys C and Bashill AT (2006) A framework for the assessment of the creativity of product design teams. Journal of Engineering Design, 17, (2): 121141.

Shah JJ, Vargas Hernandez N and Smith SM (2003) Metrics for measuring ideation effec tiveness. Design Studies, 24: 111134.

Shai O, Reich Y, Hatchuel A, Subrahmanian E (2013) Creativity and scientific discovery with infused design and its analysis with C-K theory. Research in Engineering Design 24 (2):201 214.

Suh NP (1990) Principles of Design Oxford University Press,

Torrance EP (1988) The Nature of Creativity as Manifest in its Testing. In Sternberg, R.J., ed. The Nature of Creativity Cambridge University Press, Cambridge, England.

Weisberg RW (1999) creativity and Knowledge: A Challenge to Theories. In Sternberg, R.J., ed. Handbook of Creativity, pp. 226250 Cambridge University Press, cambridge.

Ward TB, Smith SM and Finke RA (1999) Creative Cognition. In Sternberg, R.J., ed. Handbook of Creativity, pp. 189212 Cambridge University Press, Cambridge. 